December 2011

\title{
Beyond the Walled Garden: LIS Students in an Era of Participatory Culture
}

Michael Stephens

San Jose State University, mstephens7@mac.com

Follow this and additional works at: https://scholarworks.sjsu.edu/ischoolsrj

Part of the Library and Information Science Commons

\section{Recommended Citation}

Stephens, M. (2011). Beyond the Walled Garden: LIS Students in an Era of Participatory Culture. School of Information Student Research Journal, 1(2). https://doi.org/10.31979/2575-2499.010202 Retrieved from https://scholarworks.sjsu.edu/ischoolsrj/vol1/iss2/2

This article is brought to you by the open access Journals at SJSU ScholarWorks. It has been accepted for inclusion in School of Information Student Research Journal by an authorized administrator of SJSU ScholarWorks. For more information, please contact scholarworks@sjsu.edu. 
Beyond the Walled Garden: LIS Students in an Era of Participatory Culture

I recently participated in a meeting convened at the Salzburg Global Seminar in Austria. For five days, over 50 librarians and museum professionals from all over the world gathered to critically examine the impact of participatory culture on library and museum work. The event was sponsored by both the seminar and the Institute of Museum and Library Services. Participatory culture, defined by Henry Jenkins in Confronting the Challenges of Participatory Culture (2006), "is a culture with relatively low barriers to artistic expression and civic engagement, strong support for creating and sharing one's creations, and some type of informal mentorship whereby what is known by the most experienced is passed along to novices" (p. 3). When barriers fall away, participation is possible.

The seminar included presentations, working groups, and discussions centered around how library and museum service should adapt to an environment in which participation is not only possible, but encouraged. The working group I joined developed curricula for new professionals in both arenas. One aspect we highlighted was the importance of engaging with technology. Within that area were three skills our group strongly believed future professionals should possess: the ability to engage and evolve with technology, the ability to impart technology to cross-generational communities, and the ability to create and maintain an effective virtual presence.

On breaks from the intensive work, I walked the grounds of the Schloss Leopoldskron, home of the Salzburg Global Seminar, beside a lovely lake. In the gardens of the Schloss, I considered the concept of the "walled garden." This phrase has come to represent closed information technology systems or virtual spaces inaccessible to outsiders. The garden is safe from outside influences and those inside can flourish if tended. But the wall is also a barrier to outside participation. If students spend all of their time in a classroom or within the virtual walls of a closed learning management system (LMS), the potential benefits of accessing and experiencing their forthcoming professional environment will decrease. I also believe the skills and abilities detailed above flourish best when learners are participating directly with the wider community. There will always be a place for the classroom and the LMS, but balancing that environment with experience beyond the walled garden should be part of the learning process as well.

Jenkins (2006) notes that we have moved from the passivity of media spectatorship to a more engaged and inclusive environment because of the twoway nature of communication technologies now available. I have argued that library and information science (LIS) students should be exposed to these open networks of sharing, discourse, and participation. Going beyond the walled garden affords students the chance to learn from others already established in our 
wide and diverse field. The potential is present as well to share burgeoning research and new ideas culled from scholarly pursuits. Considering LIS education through the lens of Jenkins' concepts of participatory culture strengthens this argument.

\section{Artistic Expression and Civic Engagement}

The possibilities for artistic expression via digital technologies provide opportunities to those so inclined to create, remix, reuse, and mash up ideas of all kinds. The age of the YouTube "star" gives way to an environment where ideas and values can be questioned and explored; this transcends pop culture to something deeper. Witness the "It Gets Better" project videos (IOLA Foundation $\mathrm{d} / \mathrm{b} / \mathrm{a}$ It Gets Better Project, 2011) or the recent upload by a young, bullied, gay teen (Mowry, 2011). He holds a hand-lettered notecard up, tears streaming down his face: "I have a million reasons to be here."

Information professionals must understand what this change means for the creation, authority, sharing, and dissemination of information throughout the networks. They may be called upon to create physical and virtual spaces for this type of conversation. They may be asked to teach users how these tools work and how to share.

Civic engagement with the profession as well as with the community of information users is also a reality before graduation. I am reminded of the virtual internship program at SJSU SLIS in which students can work and learn in any number of unique and entirely online situations.

\section{Sharing Creations}

The Web has changed everything. The possibilities for sharing via information technologies and social networking allow LIS students to put course deliverables online for evaluation and feedback by classmates, instructors, and those beyond the virtual walls of the school. Previously, and as I recall from my own MLS program at Indiana University, papers, essays, and test responses were only shared between instructor and student. Presentations given in classrooms disappeared as soon as class was over. Now, my students' Prezis, audio recordings, Sliderocket talks, and other digital presentations live on to become part of their portfolios and serve as evidence of accomplishments for future employers. Student research shared openly can become part of the greater conversation. These possibilities for sharing enable everyone to play a role in moving our profession forward: practitioners, researchers, scholars, and students. 


\section{Informal Mentorship}

As I have written in my Library Journal column, "Office Hours," mentoring takes on new dimensions via participatory networks. Informal mentoring, in which practicing professionals engage with students via social tools, can be a catalyst for career success now and in the long term. For example, a strong mentor who shows students the best ways to navigate digital citizenship could help make or break an early career.

The other facet of informal mentoring is passing on knowledge to novices. Imagine an LIS student's research project critiqued and evaluated by practicing professionals. Helping soon-to-be librarians further understand the intricacies of research methodologies and design through constructive commentary and suggestions may yield graduates who are stronger in these necessary skills. Imagine, too, the imparting of "in the trenches" knowledge via social tools, such as Twitter or librarians' blogs, as another means to prepare future professionals. All those essential bits of information not learned in library school become available via this form of sharing. A cautionary note: There is no place for "snark," personal attacks, or overwrought negativity in these participatory spaces. Criticism is only helpful when it moves everyone forward.

\section{Contributions Matter}

It makes me happy to see students, especially those who have taken my classes, lauded in the professional networks for their contributions. When an author has commented on a student's blog post or a notable library figure "retweets" a student's Twitter post, these actions prove that everyone can be a part of the discussion. Value is present from all who participate. The notion that only professional librarians' opinions matter, for example, loses strength as everyone contributes.

The contributions of original research by graduate students can also be part of the ongoing, scholarly conversation within our field. A strong foundation in research methods prepares students - and not just those interested in academic libraries - for performing user studies, analysis of survey data, and other inquiries.

Consider, for example, the wide range of backgrounds LIS students bring to their graduate education. Many who are embarking on second careers may have insights and ideas that might benefit the greater community. Offering a mechanism for sharing and feedback, such as $S R J$, gets their voices into the mix as soon as possible. 


\section{Social Connections}

Finally, Jenkins (2006) notes that feeling connected to a larger group is a benefit and affordance of participatory culture. Establishing these connections during library school prepares graduates for future networking throughout their careers. It also creates the potential for success in finding a position. Not being connected, not participating, not having that understanding, I would argue, yields a negative result. How would this graduate respond in an interview when asked: "What social networks do you use professionally?"

Reviewing our proposed curriculum after the Salzburg program has led me to consider more ways in which I might encourage participation in the broader community for LIS students. It also helps to crystallize some ideas concerning the abilities noted above. I would argue that all graduating LIS students should prepare themselves for a participatory professional culture by nurturing a few essential qualities.

\section{A Willingness to Learn and Explore}

Transformative learning marks shifts in a learner's ideas or views of the world as they encounter new knowledge or tools. The ability to engage and evolve with various forms of technology is key for all information professionals. Learning must always continue, long after graduate school and throughout a career. The creation of one's personal learning network (PLN) should begin in graduate school and flourish throughout years of service. Social networks contribute to one's PLN, as do the colleagues we interact with daily. Learn from everyone and everything. Give back by sharing new knowledge and new ideas.

This means constantly looking and scanning for the next "big thing" that will impact what we do. It means looking beyond LIS topics to other areas of inquiry, including other academic disciplines, business, popular culture, and more. It also means taking on the unknown as a means to grow and learn. Exploration and its companion, play, have been foundational to programs like Learning 2.0 in libraries.

In A New Culture of Learning: Cultivating the Imagination for a World of Constant Change, Thomas and Brown (2011) argue that play, innovation, and experimentation is critical for 21 st century learning success. They also argue that the world is changing faster than ever and acquired skill sets have a much shorter lifespan in this new landscape. This is a concern for many information professionals, because technologies change so quickly. New forms of learning such as play and experimentation can ameliorate this problem. 


\section{A Willingness to Share}

Creating new knowledge, synthesizing current research, and implementing unique solutions to problems should be shared for the benefit of the profession. Sharing, begun in graduate schools in the pages of this journal, for example, sets up our future professionals to continue the process of paying it forward. I am reminded of the Library 2.011 WorldWide Virtual Conference, held in November 2011, that offered free access to virtual presentations and sharing from librarians from all over the world.

\section{A Willingness to Teach}

Just as an attitude of learning should always be present, so should an emphasis on teaching and instruction be part of the information professional's abilities. The realm of the instruction librarian or trainer has evolved to include more people than has historically been the case. I would argue that almost every position these days will include some form of imparting knowledge to others. Teaching information and technology skills to various communities across generations via various methods (e.g., in person, virtually, "just in time," etc.) could be characterized as part of the new normal.

\section{A Willingness to Participate}

Most importantly, the ability to create and maintain an effective virtual presence over time sets up future professionals to adapt and evolve as the networks do. As the tools change from blogging to Twitter, and from MySpace to Facebook, the ever present information professional keeps current and participates.

This participation should be framed within a humanist approach to user services, technology, research, and decision making. The focus on the heart that I often write about should propel libraries, museums, and information environments of all kinds.

Learning leads to sharing which leads to teaching which leads to more learning. Moving beyond the walled garden and into the constant streams of conversation enables an understanding of participation that cannot be imparted within a closed environment. Finding balance between participation and personal reflection becomes key as well for professionals and the people we serve.

Exploration and critical thinking about the possibilities of participatory culture should begin during graduate education and set professionals up to contribute successfully and with heart throughout their careers. 


\section{References}

IOLA Foundation d/b/a It Gets Better Project. (2011). It gets better project: Give hope to LGBT youth. Retrieved from http://www.itgetsbetter.org/

Jenkins, H. (2006). Confronting the challenges of participatory culture. Chicago: MacArthur Foundation.

Mowry, J. (2011, August 10). Whats goin on.. [Video file]. Retrieved from http://www.youtube.com/watch?v=TdkNn3Ei-Lg

Thomas, D., \& Brown, J. S. (2011). A new culture of learning: Cultivating the imagination for a world of constant change [Kindle version]. Retrieved from http://www.amazon.com 